\title{
COMUNICAÇÃO E EDUCAÇÃO - A EXPLOSÃO DAS MÍDIAS NA SOCIEDADE DA INFORMAÇÃO ${ }^{1}$
}

\author{
$\mathrm{CHAO}$, Adelaide Rocha de La Torre ${ }^{2}$ \\ SILVA, Alessandra ${ }^{3}$
}

\begin{abstract}
RESUMO
Este artigo vem refletir sobre a "explosão" das novas mídias e tecnologias na sociedade de informação contemporânea - seus impactos nos processos educacionais. Diante do cenário da aprendizagem em EAD, propomos uma discussão sobre a importância da capacitação docente diante de alunos "nativos digitais" em busca do conhecimento e formação profissional. A aprendizagem pelo digital configura-se em um processo irreversível e, neste contexto, propomos uma análise entre a Comunicação e as ferramentas de Educação que a atualidade nos impõe, através das novas tecnologias da informação e comunicação - NTIC's.
\end{abstract}

PALAVRAS-CHAVE: Educação a distância - Ambientes virtuais - Comunicação.

\begin{abstract}
This article aims at reflecting on the boom of new media and technologies in the contemporary information society as well as their impact on educational processes. Given the scenario of learning in $\mathrm{ODL}$, we propose a discussion on the importance of teacher training on the "digital natives" in search of knowledge and training students. Learning b on digital sets in an irreversible process and in this context, we propose an analysis of the communication and education tools that today imposes on us through the new technologies of information and communication - NTIC's.
\end{abstract}

KEYWORDS: Distance education - Virtual environments - Communication.

\footnotetext{
1 Este artigo é parte do trabalho final de conclusão de curso da pós-graduação latu senso em PIGEAD pelo LANTE/UFF (Laboratório de Novas Tecnologias da Universidade Federal Fluminense em novembro de 2013.)

${ }^{2}$ Publicitária e professora, graduada em Comunicação Social (UCSAL/BA), especialista em Docência do Ensino Superior (UCAM) e Planejamento, Implementação e Gestão da EAD (Lante/UFF), mestranda em Comunicação (UERJ). E-mail: adelaide.chao@gmail.com

3 Professora no Ensino Fundamental e Médio (SEE-MG), graduada em Letras (Fundação Dr. Pedro Leopoldo/MG), especialista em Planejamento, Implementação e Gestão da EAD (Lante/UFF). E-mail: prof.alessandrasilva@hotmail.com
} 
O acesso à educação no ambiente virtual permitiu o desenvolvimento da aprendizagem, eliminando algumas barreiras como o uso da autonomia, o deslocamento físico e o tempo. Agora, por meio das novas tecnologias da informação e da comunicação, é possível ampliar os meios e as formas de conhecimento, além de contribuir com o outro, a partir do momento em que o indivíduo participa de um processo de interação em que acontecem trocas de experiências, socialização, elaboração de produções textuais e a colaboração entre os pares.

Numa reflexão sobre a tal "explosão das mídias na Sociedade da Informação", é importante analisar os termos desta expressão para evidenciar um atual modo de reinventar a educação, os usos de práticas pedagógicas e comunicacionais comentadas por diversos autores, tanto na Educação como na Comunicação. No cotidiano acadêmico, percebe-se o uso natural e "onipresente" destas ferramentas, compartilhando conhecimento através da interdisciplinaridade de conteúdos (Assmann,2000).

Para um entendimento mais direto do conceito de Informação, Muniz Sodré (2002) recobre uma variedade de formas (filmes, imagens, notícias, sons, etc.) definidas como "fonte de dados", tecnicamente chamado de BIT e mercadologicamente chamado de PRODUTO. Para o autor, a "Sociedade da Informação" vem a ser uma onda "planetarista" da Globalização, preocupada apenas com a velocidade com que ocorrem as trocas informacionais (processos distributivos de capitais e mensagens).

Comparando a "Revolução da Informação" com a Revolução Industrial do século XIX - é possível perceber que, enquanto na modernidade, o avanço das tecnologias se refletia no domínio do ESPAÇO - ferrovias - e levava pelas estradas de ferro a modernização e avanços sociais, econômicos, culturais como marco do crescimento, na con- temporaneidade, este avanço se reflete no domínio do VIRTUAL - as infovias ${ }^{4}$ - vias de informação que levam através das "estradas midiáticas", o conhecimento, a democratização e expansão do capitalismo etc. Nesta metáfora, a comunicação deixa de ser linear (como nas ferrovias) e passa a ser em rede (como na Internet, por exemplo). Para Sodré (2002), o avanço não é da ordem da técnica nos processos sociais, e sim das relações intensificadoras destas novas tecnologias com o fluxo temporal. A partir do computador, surge uma nova forma de vida midiática - a tecnocultura - uma cultura da simulação ou do fluxo, mediada por novas técnicas. A convergência digital reduz as barreiras materiais, ampliando o mercado comunicacional através da unificação e novos usos de várias mídias (televisão, rádio, jornal, internet, telefonia móvel, etc.). Estes reflexos se dão nas esferas de relações sociais e de consumo nos seus mais variados aspectos, inclusive na Educação.

Compreender os conceitos de Comunicação e Informação significa não confundir com a ideia de transmissão, de "difusão cultural" para a expansão das tecnologias da informação e da comunicação, ou seja, a combinação do processamento de dados com a eletrônica e as telecomunicações. A Comunicação configura-se como forma de vida social ou um ecossistema tecnológico com valores humanos pautados pela realização eletrônica (tablets, smartphones, celulares, tv interativa, etc.) (Sodré, 2002). O conceito de Comunicação ainda está associado ao conjunto de meios de transmissão e codificação de sinais (principalmente pelos meios de comunicação de massa), mas é importante ressaltar os conceitos de Cooley

\footnotetext{
${ }^{4}$ Sodré refere-se ao conceito de Infovias (vias informacionais) citado por Manuel Castells em "A Sociedade em Rede: A Era da Informação: Economia, sociedade e cultura". Volume 1, Editora Paz e Terra. São Paulo, 1999.
} 
(1909, p.63), sociólogo e psicólogo social que definia a Comunicação como o mecanismo de existência e desenvolvimento das relações humanas, incluindo o tempo, espaço, corpo, sentimentos - todo tipo de vinculação humana. A partir do conceito de "Comunicação Midiatizada", defendida por Miège em meados do século $X X$, é que a Informação ganha novos meios de difusão e interação através da articulação com os meios de comunicação..

Explicando estes conceitos, Sodré assinala o equívoco acadêmico da distinção entre "sociedade da comunicação" e "sociedade da informação", como se fossem etapas diferentes de um processo evolutivo. É preciso preservar o sentido original de Informação, que "é dar estrutura ou forma à matéria, enquanto Comunicação diz respeito à constituição do comum humano." A informação pode ser armazenada e a comunicação não.

A interação entre informação e meios para comunicá-la é que constitui a Sociedade da Informação. O acesso já não tem mais fronteiras. Para Sodré (2002), a Sociedade da Informação constitui novas formas de comunicação - interação entre tecnologia e mercado.

Em consonância a este pensamento, Assman (2000) aponta para a necessidade da "sociedade da informação precisar tornar-se uma sociedade aprendente", através das experiências de aprendizagem complexas e cooperativas e projetos transdisciplinares de pesquisa. Existe a "onipresença" destas novas tecnologias no cotidiano das diferentes sociedades que buscam, em comum, mais conhecimento, interação, informação, ainda que existam riscos de discriminação e desumanização, já que nem todos têm as mesmas possibilidades e acessos (cultural, social, econômico, políticos e educativos) a novos conhecimentos. Para o autor, a sociedade da informação está disposta a "intensificar o pensamento complexo, interativo e transversal criando novas formas de conhecimento através de trocas de sensibilidade solidária".

Para definir Sociedade da Informação, o autor analisa os conceitos de dados, informação e conhecimento, para então entrelaçá-los à produção de conhecimento compartilhado, principalmente a baixo custo. Assmann (2000) elucida que no futuro possa haver modelos diferentes de sociedade de informação, a exemplo dos modelos de sociedade industrializadas. Mas enfatiza que o mais importante é o desencadeamento de um vasto e contínuo processo de aprendizagem - planejada, monitorada, reforçando seu caráter democrático.

As novas tecnologias ampliam o potencial cognitivo do indivíduo, que não significa estar exposto à "avalanche" de informações, mas preparar-se para decodificá-las (como um filtro de interesses) - a mistura da tecnologia e da lógica, resultando na inteligência coletiva ${ }^{5}$ (LEVY, 1999), gerando a inclusão social e digital, modificando, inclusive, as formas criativas das atividades intelectuais.

É irreversível - a Educação faz parte desta "Sociedade da Informação". As novas tecnologias de informação e comunicação estão afixadas no cotidiano da sociedade, nas trocas comunicacionais e, principalmente, nos processos educacionais na contemporaneidade. Um aspecto social positivo é que estas tecnologias incluem, agregam conhecimento e pessoas. Bernini et al. (2009) refletem sobre uma nova postura de professores e alunos para questões como responsabilidade de conteúdo, trocas e cre-

\footnotetext{
${ }^{5}$ Inteligência Coletiva é um termo usado por Pierre Levy (1999), em muitas de suas obras, para explicar o compartilhamento de funções cognitivas como a memória, a percepção e o aprendizado para gerar conhecimento através da internet.
} 
dibilidade nos ambientes de aprendizagem. As NTICS estão muito além de "aulas-show" na transmissão de conteúdos. É uma mudança de paradigma, principalmente na ambientação para explorar os recursos disponíveis (o interesse e a capacitação do "fazer diferente"). A velocidade e a diversidade exacerbada de informação, oriunda das mídias de massa e das NTIC's, devem despertar uma análise crítica de conteúdo e ideologias. Deve haver um filtro consciente para o aprender e para o ensinar.

A (re) significação do que seja ENSINAR, diante destas novas ferramentas, exige o comprometimento com as etapas de planejamento, avaliação, discussões programadas etc., sempre instigando o aluno ao conhecimento, à curiosidade e à pesquisa - mas sem haver uma banalização do aprendizado, já que não há garantias de trocas completas na construção do conhecimento e nos desafios da Educação.

Ainda que as ferramentas de monitoramento e controle nos ambientes virtuais sejam aprimoradas e eficientes, o desafio do docente será permanente. $\mathrm{E}$ este desafio está na reinvenção da docência e do aprendizado, em reinterpretar os modos de fazer a Educação. Há uma nova ordem educacional na Sociedade da Informação. A escolarização se dá em qualquer lugar, independe do espaço físico, principalmente no campo virtual. A escola transcende as paredes, lousas, giz de cera, papel etc. (Sodré, 2012).

Sob este ponto de vista, o autor reflete sobre uma "nova condição humana" em comunicar-se e aprender. Esta urgência de mudança reflete no papel do professor diante de uma dinâmica cognitiva de sensibilidade. É necessário reinventar a figura do professor com uma nova função "iniciática" conduzindo o aluno aos princípios da ética, saberes, consciência mais madura do agir e pensar.
A Educação está para o professor, assim como paternalizar está para pai e/ou mãe; o desafio da tecnologia está no pensar no termo logia, na lógica da técnica, numa outra ordem (Sodré, 2012). É ter a sensibilidade para acolher uma demanda qualquer do outro, ainda que através de recursos tecnológicos. É necessário pensar a partir do afetual, mostrando que o sensível tem uma lógica própria que aparece junto ao equipamento. Para Muniz Sodré (2012), educar para o sensível é educar para a diversidade, através da ecologia dos saberes. Eis o desafio maior da Educação: refletir a transdisciplinaridade dos saberes diversos, exigidas nos currículos, conteúdos e no professor (aquele que inicia, apresenta e desperta os saberes).

A educação a distância é um processo analítico, planejado para a transmissão de valores estabelecidos. Contempla a possibilidade de outros modos de produzir e pensar para que possa emergir o novo. É uma preparação permanente de si mesmo, para a construção de uma transformação coerente da ordem social. Educar-se significa preparar-se para a cidadania plena.

Assmann (2000) alerta que o novo professor, envolvido neste universo tecnomidiático, deverá sair da "zona de conforto" - de um transmissor de conteúdo para um intermediador de conhecimento, "mentores e instigadores ativos de uma nova dinâmica de pesquisa/aprendizagem".

A EAD ${ }^{6}$ está abrindo portas cada vez mais próximas dos alunos que antes não tinham acesso a uma universidade por diversos motivos e um deles, talvez o mais comum entre as pessoas, é a falta de tempo para se dedicar a um curso presencial.

Visto que o acesso à aprendizagem mudou com o uso das NTICs (novas tecno-

${ }^{6}$ EAD (abrev.) - Educação a Distância. 
logias da informação e comunicação), é importante tratar dos mecanismos que contribuem para o avanço da modalidade "Educação a Distância". É imprescindível organizar as formas de planejamento, implementação e gestão da $E A D$, para saber com clareza como desenvolver, pensar, propor, criar, organizar, gerenciar e estabelecer metodologias de ensino que alcancem o aluno além da sala de aula presencial.

Segundo Moran et al. (2000), cada inovação bem sucedida modifica os padrões anteriores e muda o patamar de exigência do indivíduo. Essa ideia realmente é visível através do ensino disponibilizado via EAD, pois o papel do profissional da educação muda, já que ele deixa de ser um mero transmissor de saberes prontos, passando a ser o mentor e instigador de uma nova dinâmica de aprendizagem. Para que consiga atingir seu aluno com eficácia, é necessário o gerenciamento do conteúdo, a gestão dos usuários, a infraestrutura de comunicação e distribuição e a produção de conteúdos didáticos, interativos e virtuais, mecanismos esses de suma importância para levar o aluno a ser o gestor de sua própria aprendizagem.

Os professores de EAD precisam, então, repensar seus papéis diante das NTICs, fazendo com que os ambientes virtuais de aprendizagem se desenvolvam e assumam características e modelos diferentes, o que faz com que os profissionais dessa modalidade tenham que se capacitar, a cada dia, para poderem fazer uso das ferramentas tecnológicas que permeiam o aprendizado em EAD, de forma a atingir qualificação profissional com qualidade e mostrar o real impacto que ela proporciona à educação.

Segundo Moran et al.(2000), o importante é cada professor encontrar, na tecnologia, o que lhe auxilie a comunicar-se bem para os alunos terem um aprendizado completo. Logo, o domínio das NTICs é fun- damental quando se quer expandir o conhecimento através das mídias de comunicação. O aluno contemporâneo é um nativo digital e a tecnologia faz parte de seu cotidiano, constantemente. E os educadores precisam acompanhar este movimento de inclusão digital.

Para que utilizar ferramentas que não dominamos? É inviável tentar passar um conhecimento a partir de um equipamento do qual não temos um devido controle. Assim, por exemplo, não conseguiremos atingir um aluno de EAD se não conseguirmos utilizar as NTICs com eficácia.

É de extrema importância o domínio destes mecanismos - plataformas, correio eletrônico, mensagens instantâneas, fóruns, salas de bate-papo e etc., pois o aluno estará diretamente ligado a eles e sua permanência, ou não, em um curso a distância se dará devido à maneira como será conduzido por seu professor/tutor.

Ainda é comum a evasão discente em EAD pela inoperância ou inabilidade com ferramentas digitais. Se, para o docente, é complicado entender as ferramentas que utiliza, fica impossível tirar as dúvidas dos alunos e até mesmo ajudá-los a se desenvolverem sozinhos.

Santos et al. (2012, p.03) nos lembram a importância dos Ambientes Virtuais de Aprendizagem nas metodologias de ensino e nos seus reflexos de aprendizagem na sociedade contemporânea:

Os $\mathrm{AVAs}^{7}$ foram desenvolvidos para serem utilizados pedagogicamente na educação on line. Dotados de interfaces comunicacionais (síncronas e assíncronas) e de conteúdo, estes se configuram espaços de convivência e compartilhamento de saberes, potencializando a autoria, a autonomia, a inte-

\footnotetext{
${ }^{7}$ AVAs (abrev.) - Ambientes Virtuais de Aprendiza-
} gem. 
ratividade (SILVA, 2010) e a remixagem de informação (LEMOS, 2008).

Utilizando a criatividade e inovação nos fazeres educacionais, Maldonatto e Dell 'Orco (2010) ressaltam que a inovação é uma capacidade de a mente inferir significados inusitados, a partir de informações aparentemente banais, produzindo respostas divergentes e criativas através de cenários e soluções diferentes de maneira quase casual.

Para os autores (Santos et.al. 2012), o essencial, neste momento, é discutir a docência na cibercultura mediada pela mobilidade e ubiquidade da comunicação, através das redes sociais, dispositivos móveis e ambientes virtuais de aprendizagem, articulando-os à construção do conhecimento. As autoras ainda ressaltam que as possibilidades de recursos educacionais abertos (REA) efetivam a hibridização de espaços geográficos e virtuais associados, propiciados pelas tecnologias sociais e em rede. Ou seja, há uma quebra de fronteiras entre cidades, espaços físicos, redes sociais e ciberespaço em tempos de cibercultura e as interfaces web 2.0 cumprem esta função através de softwares livres, softwares sociais, dispositivos móveis (a exemplo de tablets, notebooks, smartphones), wikis, podcasts, internet de alta velocidade (3G e 4G). Segundo as autoras, vale ressaltar que

(...) a integração contínua do corpo físico ao espaço virtual é uma realidade da sociedade da informação. Assim, a delimitação existente entre o mundo físico e o ciberespaço é rompida, não sendo possível distinguir onde começa e onde termina cada um. (SANTOS et. al, 2012).

A reflexão de Santaella (2007, apud Santos et al., 2012) está em sintonia com o pensamento de Sodré (2012) sobre o fato de a cibercultura fazer parte da cultura contemporânea, exercendo um papel mediador e inevitável. As relações sociais, e incluímos aqui as relações de aprendizagem, ultrapassam a esfera do ciberespaço e estruturam as relações sociais entre cidades, escolas, universidades, empresas, grupos, enfim, o cotidiano (Santos et. al, 2012).

Neste contexto, onde o espaço físico sugere uma menor relevância para a educação on line, as autoras reforçam a necessidade e a urgência da formação continuada para professores que atuam na cibercultura educacional. A mediação docente deve ser provocadora, como sugerem Santos (2012) e Sodré (2002), através de uma nova héxis ${ }^{8}$ educativa. Retomando autores antigos como Aristóteles, Sodré postula que "Educar implica ir além da repetição contingente de um costume pela aceitação dos impulsos de liberdade que transformam ethos ${ }^{9} \mathrm{em}$ hexis." (2002, p.85).

Tais habilidades, atreladas às mudanças socioculturais provocadas pelas novas tecnologias da informação e comunicação (NTIC's), propõem aos docentes a ampliação do conhecimento em novos espaços de interação e de aprendizagem. As autoras sugerem que o docente "precisa pesquisar práticas colaborativas que tragam fundamentos e outras metodologias nos diversos espaçostempos de aprendizagem." (SANTOS et. al, 2012: p.03). Relembrando os conceitos de Castells (1999, apud SANTOS et.al, 2012, p.4), "a formação docente para uma

\footnotetext{
${ }^{8} \mathrm{O}$ termo héxis, vem do latim e significa "habilidade". Para Muniz Sodré, a hexis educativa afirma-se o sentido de uma prática sem automatismo, uma ação que exprime mudança, transformação. O sujeito se apropria dos costumes herdados e tradicionalmente reproduzidos com a firme decisão de produzir atos justos, equilibrados e propriamente éticos (ações voltadas para o bem comum) (Sodré, 2002, p.85).

${ }^{9} \mathrm{O}$ termo ethos é de origem grega e significa "caráter", "o modo de ser de".
} 


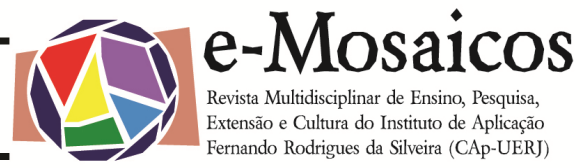

prática colaborativa exige o reconhecimento das mudanças trazidas pela sociedade em rede." E na Educação não é diferente, estando dentro e fora dos espaços das instituições de ensino, sem restrições.

A diversidade sociocultural e econômica brasileira não permite que se estabeleça um padrão de utilização, permitindo a criatividade nas metodologias e uso de vários recursos educacionais, a exemplo dos softwares livres como o Linux e outros REA, que são qualquer tipo de material educacional que está disponível para (re) uso, (re) criação, (re) significação na rede globalizada. (SANTOS, 2012, p.5).

Deste modo, a docência on line está inserida em um cenário criativo, múltiplo, diverso e mediador na construção do conhecimento. Cenário da Sociedade da Informação, midiatizada e múltipla, para alunos e professores.

\section{REFERÊNCIAS BIBLIOGRÁFICAS:}

ASSMANN, Hugo. A metamorfose do aprender na sociedade de informação. Ci. Inf., Brasília, v. 29, n. 2, p. 7-15, maio/ago. 2000. Disponível em: <http://www.scielo.br/pdf/ci/v29n2/a02v29 n2.pdf>. Acesso em: 12 mar. 2013.

BERNINI, Denise Simões Dupont; BOLSONI, Evandro Paulo; SOUZA, Carlos Henrique M. de; SILVA, Marcos Antônio da. Nova abordagem nas práticas pedagógicas com o uso das NTICs na Educação Superior. In: SIMPÓSIO BRASILEIRO DE INFORMÁTICA NA EDUCAÇÃO - SBIE UFJF, 2009. Florianópolis. Anais... Florianópolis: UFSC, 2009. Disponível em: <http://wwwexe.inf.ufsc.br/ sbie2009/anai s/wmodelos.html>.Acesso em: 20 mar. 2013.

CASTELLS, Manuel. A Sociedade em Re- de: A Era da Informação: Economia, sociedade e cultura. São Paulo: Volume 1, Editora Paz e Terra, 1999.

COOLEY, Charles. Social Organization: a Study of the Larger Mind. New York: Charles Scribner's Sons, 1909.

JENKINS, Henry. A cultura da convergência: a colisão entre os velhos e novos meios de comunicação. São Paulo: Editora Aleph, 2009.

KENSKI, Vani Moreira. Do ensino interativo às comunidades de aprendizagem. Em direção a uma nova sociabilidade em Educação. Revista de Educação e Informática - Acesso, São Paulo, v. 15, p. 49-59, 2001.

LEVI, Pierre. Cibercultura. São Paulo: Editora Trinta e Quatro, 1999

MALDONATO, Mauro; DELL'ORCO, Silvia. Criatividade, pesquisa e inovação: o caminho surpreendente da descoberta. B. Téc. Senac: a R. Educ. Prof., Rio de Janeiro, v. 36, n.1, jan./abr. 2010. Disponível em:

<http://www.senac.br/BTS/361/artigo1.pdf >. Acesso em: 21 mar. 2013.

MORAN, José Manuel; MASETTO, Marcos T; BEHRENS, Marilda Aparecida. Novas tecnologias e mediação pedagógica. Campinas: Papirus, 2000.

SANTOS, E.; WEBER, A.; Santos,R. \& ROSSINI, T.(2012). Docência na cibercultura: possibilidades de usos de REA. In: Okada, A. (Ed.) (2012) Open Educational Resources and Social Networks: Co-Learning and Professional Development. London: Scholio Educational Research \& Publishing. Disponível em <http://oer.kmi.open.ac.uk/ wpcontent/uploads/cap12_gpdoc.pdf> 
acesso em 08/09/2013.

SANTOS. Edméa Oliveira. Ambientes virtuais de aprendizagem: por autorias livres, plurais e gratuitas. In: Revista FAEBA, v.12, no. 18.2003 (no prelo).

SOARES, Ismar. Educomunicação: um campo de mediações. Comunicação \& Educação, São Paulo: Universidade de São Paulo(19): 12 a 24, set./dez. 2000. Disponível em:<http://200.144.189.42/ojs/ index.php/comeduc/article/viewFile/4147/388 8> Acesso em: 04 mar. 2012.

SODRÉ, Muniz. Antropológica do EspeIho: uma teoria da comunicação linear e em rede. Petrópolis: Vozes, 2002.

SODRÉ, Muniz. Reinventando a educação - diversidade, descolonização e redes. Petrópolis: Vozes, 2012.

TAVARES, Valéria Ribeiro de Carvalho. $\mathbf{O}$ ambiente inovador da EAD: agente de mudanças e transformações das práticas pedagógicas. Disponível em: <http://www.universia.com.br/materia/ materia.jsp? materia $=12902>$. Acesso em 02 abr. 2013. 